\title{
Diferentes suplementos associados à palma forrageira em dietas para ovinos: consumo, digestibilidade aparente e parâmetros ruminais
}

\author{
Different supplements associated to spineless cactus in diets for sheep: intake, apparent \\ digestibility and ruminal parameters
}

\author{
PESSOA, Ricardo Alexandre Silva ${ }^{1 *}$; FERREIRA, Marcelo de Andrade ${ }^{1}$; SILVA, \\ Fabiana Maria da ${ }^{1}$; BISPO, Safira Valença ${ }^{2}$; WANDERLEY, Walmir Lima ${ }^{3}$; \\ VASCONCELOS, Priscylla Carvalho
}

\footnotetext{
${ }^{1}$ Universidade Federal Rural de Pernambuco, Departamento de Zootecnia, Recife, Pernambuco, Brasil.

${ }^{2}$ Universidade Federal da Paraíba, Departamento de Zootecnia, Areia, Paraíba, Brasil.

${ }^{3}$ Instituto Federal de Pernambuco, Barreiros, Pernambuco, Brasil.

*Endereço para correspondência: ricardo.pessoa@dz.ufrpe.br
}

\section{RESUMO}

Objetivou-se avaliar o consumo, a digestibilidade aparente dos nutrientes e os parâmetros ruminais de ovinos alimentados com dietas à base de palma forrageira, bagaço de cana-de-açúcar e ureia associados a diferentes suplementos. Foram utilizados cinco ovinos sem padrão racial definido, machos, não-castrados, fistulados no rúmen. Os animais foram distribuídos aleatoriamente em quadrado latino 5 x 5, com cinco animais (linhas) e cinco períodos (colunas). Cada período teve duração de 13 dias. A ração sem suplemento foi composta de $67,6 \%$ de palma forrageira, $27,7 \%$ de bagaço de cana-de-açúcar in natura, 2,7\% de mistura ureia:sulfato de amônio (9:1) e 2,0\% de mistura mineral, em base da matéria seca (MS). Os demais tratamentos consistiram na adição de um suplemento à ração ao nível de $0,4 \%$ do peso corporal, composta por: farelo de trigo, farelo de soja, farelo de algodão ou caroço de algodão. Não foram observados efeitos da associação dos suplementos sobre os parâmetros avaliados, sendo: 3,29\%, 60,61\%, 76,37\%, 6,51 e $11,85 \mathrm{mg} / 100 \mathrm{~mL}$ os valores médios observados para o consumo de MS em função do peso corporal, digestibilidades da MS e da $\mathrm{PB}, \mathrm{pH}$ e amônia ruminal, respectivamente. A escolha do suplemento deve estar associada à disponibilidade e ao custo.

Palavras-chaves: amônia, Opuntia ficus indica Mill, pH, suplementação

\section{SUMMARY}

The study was conducted with the objective to evaluate the intake, apparent digestibility of the nutrients and of ruminal fermentation characteristics of sheep fed diets based on spineless cactus, sugar cane bagasse and urea associated to diferents supplements. Five noncastrated male sheep were allotted to a $5 \times 5$ Latin square design, with five animals (lines) and five periods (columns). Each experimental period last 13 day. The ration without supplement was composed of $67.6 \%$ of spineless cactus, $27.7 \%$ of sugar cane bagasse, $2.7 \%$ of urea:ammonium sulphate mixture $(9: 1)$ and $2.0 \%$ of mineral mixture, in dry matter (DM) basis. The other treatments consisted of the addition of a supplement to the ration $(0,4 \%$ of body weight), being: wheat meal, soybean meal, cottonseed meal or whole cottonseed. Were not observed effects of supplement association on the evaluated parameters, being: $3.29 \%, 60.61 \%, \quad 76.37 \%, 6.51$ and $11.85 \mathrm{mg} / 100 \mathrm{~mL}$ the means value for intake of DM (\% of body weight), digestibility of DM and $\mathrm{CP}, \mathrm{pH}$ and ruminal ammonium, respectively. The choice of supplement should be associated with the availability and cost.

Keywords: amonium, Opuntia ficus indica Mill, $\mathrm{pH}$, supplementation 


\section{INTRODUÇÃO}

O semiárido brasileiro é um dos maiores e mais populosos do mundo. Estende-se por $1.000 .000 \mathrm{~km}^{2}$ e vivem nessa região mais de 21 milhões de pessoas. A precipitação pluviométrica é de $750 \mathrm{~mm}$ anuais, em média, mas a chuva é má distribuída física e temporalmente. A pecuária contribui para a estabilidade econômica do produtor, uma vez que em tempos de estiagem apresenta uma redução bem menos pronunciada que a agricultura.

A alimentação animal deve basear-se na utilização de recursos forrageiros adaptados às condições edafoclimáticas da região. Neste sentido, merece destaque a palma forrageira, cultura largamente difundida no Nordeste. Suas principais limitações, como compostos nitrogenados e fibra em detergente neutro, podem ser reduzidas com a inclusão na dieta de alimentos de baixo custo e de fácil aquisição. Sendo a palma rica em carboidratos não fibrosos e possuindo, relativamente, baixos teores de nitrogênio, esta também pode estar associada à ureia com o intuito de elevar seu teor proteico.

Os microrganismos que degradam a fração fibrosa no rúmen exigem apenas amônia como fonte nitrogenada para o crescimento, enquanto aqueles que degradam carboidratos não fibrosos exigem aminoácidos e peptídeos, além da amônia. Os processos de degradação celulolítica e do crescimento das bactérias devem ser enfatizados no estudo das interações com outras espécies microbianas, as quais fornecem compostos essenciais, como vitaminas do complexo $\mathrm{B}$ e ácidos graxos de cadeia ramificada, que funcionam como precursores de aminoácidos essenciais, ácidos graxos estruturais e alguns aldeídos (BRYANT, 1973). Nesse sentido, a suplementação da dieta com fontes de proteína verdadeira, além do nitrogênio não proteico, pode melhorar o desempenho animal.

O fornecimento de alimento concentrado formulado a base de vários ingredientes exige conhecimento técnico e disponibilidade de recursos quase sempre não condizentes com a realidade do semiárido. Os efeitos da inclusão de um único suplemento à dieta, em oposição a um concentrado balanceado, devem ser avaliados, pois, a estratégia associa praticidade e pode contribuir para redução dos custos totais visando à sustentabilidade do sistema de produção.

Objetivou-se avaliar em ovinos, o efeito da inclusão de farelo de soja, farelo de trigo, farelo de algodão e caroço de algodão, como suplementos para dietas à base de palma forrageira sobre 0 consumo, a digestibilidade aparente dos nutrientes, o pH e nitrogênio amoniacal ruminais.

\section{MATERIAL E MÉTODOS}

O experimento foi conduzido no galpão de digestibilidade do setor de CaprinoOvinocultura do Departamento de Zootecnia da Universidade Federal Rural de Pernambuco, em Recife - PE. Foram utilizados cinco ovinos sem padrão racial definido, machos, nãocastrados, fistulados no rúmen, com peso corporal médio de $22,8 \mathrm{~kg}( \pm 3,5)$, mantidos em gaiolas individuais dotadas de comedouro, bebedouro e cocho para fornecimento de sal.

Os animais foram distribuídos aleatoriamente em quadrado latino $5 \mathrm{x}$ 5 , com cinco animais (linhas) e cinco períodos (colunas). Cada período teve duração de 13 dias, sendo sete para adaptação ao manejo e dietas e seis para 
Rev. Bras. Saúde Prod. Anim., Salvador, v.14, n.3, p.508-517 jul./set., 2013 http://www.rbspa.ufba.br ISSN 15199940

coleta de dados e amostras (SOARES et al., 2004).

A espécie de palma utilizada foi a Opuntia ficus indica Mill cv. Gigante, fornecida aos animais associada aos demais ingredientes na forma de dieta completa. Nas Tabelas 1 e 2 estão apresentadas, respectivamente, a composição nutricional dos ingredientes das dietas experimentais, as proporções dos ingredientes bem como a composição nutricional das dietas totais.

Tabela 1. Composição nutricional dos ingredientes das dietas experimentais

\begin{tabular}{lcccccc}
\hline \multirow{3}{*}{ Nutriente } & \multicolumn{6}{c}{ Alimento } \\
\cline { 2 - 7 } & $\begin{array}{c}\text { Palma } \\
\text { Forrageira }\end{array}$ & $\begin{array}{c}\text { Bagaço de } \\
\text { Cana }\end{array}$ & $\begin{array}{c}\text { Farelo de } \\
\text { Trigo }\end{array}$ & $\begin{array}{c}\text { Farelo de } \\
\text { Soja }\end{array}$ & $\begin{array}{c}\text { Farelo de } \\
\text { Algodão }\end{array}$ & $\begin{array}{c}\text { Caroço de } \\
\text { Algodão }\end{array}$ \\
\hline MS (\%) & 9,39 & 80,93 & 88,51 & 89,00 & 91,10 & 93,34 \\
MO $^{1}$ & 88,08 & 95,52 & 94,13 & 92,29 & 93,27 & 96,62 \\
PB $^{1}$ & 3,82 & 1,65 & 16,60 & 48,50 & 39,70 & 26,70 \\
EE $^{1}$ & 2,48 & 1,83 & 4,02 & 1,94 & 0,90 & 21,08 \\
FDN $_{\text {CP }}$ & 29,07 & 82,27 & 41,37 & 10,67 & 33,25 & 44,93 \\
CNF $^{1}$ & 52,71 & 9,77 & 32,14 & 31,18 & 19,42 & 3,91 \\
FDA $^{1}$ & 22,50 & 67,20 & 15,02 & 12,29 & 24,23 & 36,62 \\
Lignina $^{1}$ & 5,32 & 14,10 & 4,30 & 1,80 & 3,00 & 7,31 \\
\hline
\end{tabular}

$\mathrm{MO}=$ matéria orgânica, $\mathrm{PB}=$ proteína bruta, $\mathrm{EE}=$ Extrato etéreo, $\mathrm{FDN}_{\mathrm{CP}}=$ fibra em detergente neutro corrigida para cinzas e proteína, $\mathrm{CNF}=$ carboidratos não-fibrosos, $\mathrm{FDA}=$ fibra em detergente ácido.

$1_{\%}$ MS.

Tabela 2. Percentual de ingredientes e composição nutricional das dietas

\begin{tabular}{|c|c|c|c|c|c|}
\hline \multirow[b]{2}{*}{ Item } & \multicolumn{5}{|c|}{ Tratamentos (\% na MS total) } \\
\hline & $\begin{array}{c}\text { Sem } \\
\text { Suplemento }\end{array}$ & $\begin{array}{l}\text { Farelo de } \\
\text { Trigo }\end{array}$ & $\begin{array}{l}\text { Farelo } \\
\text { de Soja }\end{array}$ & $\begin{array}{l}\text { Farelo de } \\
\text { Algodão }\end{array}$ & $\begin{array}{c}\text { Caroço de } \\
\text { Algodão }\end{array}$ \\
\hline Palma Forrageira & 67,6 & 62,8 & 62,8 & 62,8 & 62,8 \\
\hline Bagaço de cana & 27,7 & 24,9 & 25,1 & 25,1 & 25,1 \\
\hline Ureia + sulfato de amônio & 2,7 & 2,3 & 2,1 & 2,1 & 2,1 \\
\hline Farelo de Trigo & - & 8,0 & - & - & - \\
\hline Farelo de Soja & - & - & 8,0 & - & - \\
\hline Farelo de Algodão & - & - & - & 8,0 & - \\
\hline Caroço de Algodão & - & - & - & - & 8,0 \\
\hline \multirow[t]{2}{*}{ Mistura mineral } & 2,0 & 2,0 & 2,0 & 2,0 & 2,0 \\
\hline & \multicolumn{5}{|c|}{ Composição Nutricional } \\
\hline Matéria seca (\%) & 12,6 & 13,9 & 13,9 & 13,9 & 13,9 \\
\hline Matéria orgânica $^{1}$ & 86,0 & 86,6 & 86,7 & 86,8 & 87,0 \\
\hline Proteína bruta $^{1}$ & 10,0 & 10,2 & 11,8 & 11,4 & 10,4 \\
\hline Extrato etéreo $^{1}$ & 2,2 & 2,2 & 2,2 & 2,1 & 3,7 \\
\hline Fibra em detergente neutro ${ }^{1}$ & 42,4 & 42,1 & 39,8 & 41,6 & 42,5 \\
\hline Carboidratos não fibrosos ${ }^{1}$ & 38,3 & 38,1 & 38,0 & 37,1 & 35,9 \\
\hline Fibra em detergente ácido ${ }^{1}$ & 33,8 & 32,1 & 32,0 & 32,9 & 33,9 \\
\hline Lignina $^{1}$ & 7,5 & 7,2 & 7,0 & 7,1 & 7,5 \\
\hline
\end{tabular}


A alimentação foi fornecida duas vezes ao dia (oito e 16h), ajustada diariamente de acordo com o consumo do dia anterior, de modo que as sobras representassem em torno de $10 \%$ do total ofertado, a fim de permitir ingestão voluntária e não alterar a proporção dos ingredientes.

Durante o período de coleta, amostras dos alimentos fornecidos e das sobras foram recolhidas diariamente pela manhã, pré-secas em estufa de ventilação forçada e armazenadas para análises. Ao final do experimento, foi feita amostra composta por animal, por período. Posteriormente, todas as amostras foram preparadas e analisadas quanto à composição bromatológica conforme metodologias descritas por Detmann et al. (2012).

A coleta de amostras de fezes foi realizada diretamente na ampola retal dos animais, diariamente $(0 ; 2 ; 4 ; 6 ; 8$ e 10 horas após a alimentação) - (BISPO et al., 2007), durante o período de coleta. As fezes foram pré-secas em estufa de ventilação forçada a $60^{\circ} \mathrm{C}$ e, posteriormente, processadas em moinho de peneira com crivo de $2 \mathrm{~mm}$ para futuras análises. A estimativa da produção de MS fecal foi feita utilizando-se a fibra em detergente ácido indigestível (FDAi) como indicador interno. Coletaram-se $1,0 \mathrm{~g}$ de cada amostra de suplemento e palma forrageira e $0,5 \mathrm{~g}$ de bagaço de cana, sobras e fezes. As amostras foram individualmente acondicionadas em sacos de ANKON e incubadas no rúmen de um bubalino com fístula permanente por 264 horas (CASALI et al., 2008). Após esse período, as amostras foram retiradas do rúmen, lavadas e analisadas quanto aos teores de FDA, para determinação da fração da fibra remanescente, considerada FDAi. A produção de MS fecal foi estimada pela divisão do consumo do indicador por sua concentração nas fezes. $\mathrm{O}$ coeficiente de digestibilidade aparente (CD) foi calculado utilizando a equação: $\mathrm{CD}=$ ((nutriente ingeridonutriente excretado)/nutriente ingerido). Durante os quatro últimos dias de cada período de coleta, foram colhidas amostras de fluido ruminal, via cânula, nos seguintes tempos: imediatamente antes da primeira refeição (correspondente à hora zero) e duas, quatro e seis horas após a primeira refeição. Para mensuração do $\mathrm{pH}$ seguiuse o descrito por Cabral et al. (2008). A concentração de N-NH3 no fluido ruminal foi determinada por meio de destilação com solução de hidróxido de potássio $(\mathrm{KOH}) 2 \mathrm{~N}$.

As avaliações das variáveis $\mathrm{pH}$ e concentração de amônia ruminais foram realizadas como medidas repetidas no tempo (KAPS \& LAMBERSON, 2004). Os dados foram avaliados pelo PROC MIXED SAS (SAS INSTITUTE, 2000), utilizando-se 0,05 como nível crítico de probabilidade para o erro tipo I. O seguinte modelo foi utilizado nas análises: $\mathrm{y}_{\mathrm{ijk}}=\mu+\mathrm{T}_{\mathrm{i}}+\mathrm{P}_{\mathrm{j}}+\mathrm{A}_{\mathrm{k}}+\mathrm{e}_{\mathrm{ijk}}$, em que: $\mu$ é a média do experimento; $\mathrm{T}_{\mathrm{i}}$ é o efeito do tratamento $\mathrm{i} ; \mathrm{P}_{\mathrm{j}}$ é o efeito do período j; $A_{k}$ é o efeito do animal k; $\mathrm{e}_{\mathrm{ijk}}$ é o erro experimental; sendo $\mathrm{i}, \mathrm{j}, \mathrm{k}=$ $1,2,3,4,5$.

\section{RESULTADOS E DISCUSSÃO}

A associação dos diferentes suplementos à dieta a base de palma forrageira não alterou os consumos de matéria seca, matéria orgânica e de nutrientes pelos animais, exceto 0 consumo de extrato etéreo, que se mostrou superior para o tratamento com caroço de algodão, suplemento com alto teor deste nutriente (Tabela 3 ). 
Rev. Bras. Saúde Prod. Anim., Salvador, v.14, n.3, p.508-517 jul./set., 2013 http://www.rbspa.ufba.br ISSN 15199940

Tabela 3. Consumo de nutrientes

\begin{tabular}{|c|c|c|c|c|c|c|}
\hline \multirow[b]{2}{*}{ Item } & \multicolumn{5}{|c|}{ Rações } & \multirow[b]{2}{*}{ CV $(\%)$} \\
\hline & $\begin{array}{c}\text { Sem } \\
\text { Suplemento }\end{array}$ & $\begin{array}{c}\text { Farelo de } \\
\text { Trigo }\end{array}$ & $\begin{array}{c}\text { Farelo de } \\
\text { Soja }\end{array}$ & $\begin{array}{c}\text { Farelo de } \\
\text { Algodão }\end{array}$ & $\begin{array}{c}\text { Caroço de } \\
\text { Algodão }\end{array}$ & \\
\hline $\mathrm{CMS}^{1}$ & $720,29^{\mathrm{a}}$ & $751,70^{\mathrm{a}}$ & $727,89^{\mathrm{a}}$ & $712,68^{\mathrm{a}}$ & $761,52^{a}$ & 15,81 \\
\hline $\mathrm{CMO}^{1}$ & $680,94^{\mathrm{a}}$ & $668,03^{\mathrm{a}}$ & $645,35^{\mathrm{a}}$ & $634,33^{\mathrm{a}}$ & $678,88^{\mathrm{a}}$ & 15,99 \\
\hline $\mathrm{CPB}^{1}$ & $83,68^{\mathrm{a}}$ & $84,54^{\mathrm{a}}$ & $101,39^{\mathrm{a}}$ & $92,69^{\mathrm{a}}$ & $93,64^{\mathrm{a}}$ & 14,37 \\
\hline $\mathrm{CEE}^{1}$ & $18,35^{\mathrm{b}}$ & $20,19^{b}$ & $17,74^{\mathrm{b}}$ & $18,00^{\mathrm{b}}$ & $34,39^{\mathrm{a}}$ & 9,70 \\
\hline $\mathrm{CCNF}^{1}$ & $291,64^{a}$ & $265,25^{\mathrm{a}}$ & $235,53^{\mathrm{a}}$ & $254,06^{\mathrm{a}}$ & $242,41^{\mathrm{a}}$ & 28,26 \\
\hline $\mathrm{CFDN}^{1}$ & $287,27^{\mathrm{a}}$ & $298,04^{\mathrm{a}}$ & $290,70^{\mathrm{a}}$ & $269,58^{\mathrm{a}}$ & $308,44^{\mathrm{a}}$ & 11,72 \\
\hline $\mathrm{CNDT}^{1}$ & $481,75^{\mathrm{a}}$ & $454,44^{\mathrm{a}}$ & $442,79^{\mathrm{a}}$ & $440,33^{\mathrm{a}}$ & $466,44^{\mathrm{a}}$ & 15,78 \\
\hline $\mathrm{CMS}^{2}$ & $3,37^{\mathrm{a}}$ & $3,37^{\mathrm{a}}$ & $3,16^{\mathrm{a}}$ & $3,15^{\mathrm{a}}$ & $3,39^{\mathrm{a}}$ & 14,77 \\
\hline $\mathrm{CFDN}^{2}$ & $1,26^{\mathrm{a}}$ & $1,33^{\mathrm{a}}$ & $1,27^{\mathrm{a}}$ & $1,19^{\mathrm{a}}$ & $1,37^{\mathrm{a}}$ & 10,61 \\
\hline
\end{tabular}

Médias, na linha, seguidas por letras diferentes, diferem $(\mathrm{P}<0,05)$ pelo teste Tukey.

${ }^{1} \mathrm{~g} /$ dia, ${ }^{2} \%$ do peso corporal; $\mathrm{CV}=$ coeficiente de variação.

Consumos de: $\mathrm{CMS}=$ matéria seca, $\mathrm{CMO}=$ matéria orgânica, $\mathrm{CPB}=$ proteína bruta, $\mathrm{CEE}=$ extrato etéreo, $\mathrm{CCNF}=$ carboidratos não-fibrosos, $\mathrm{CFDN}=$ fibra em detergente neutro e CNDT $=$ nutrientes digestíveis totais.

Consumos de matéria seca superiores a $3,0 \%$ do peso corporal em ovinos podem ser considerados satisfatórios por proporcionar ingestão adequada de nutrientes quando em dietas corretamente balanceadas. Bispo et al. (2007) observaram CMS de 3,9\% do peso corporal para ovinos em dietas com $56 \%$ de palma forrageira. Tegegne et al. (2007) observaram maximização no CMS e CMO em ovinos recebendo dietas com $60 \%$ de palma forrageira (4,3\% do peso corporal). Em dietas com alta proporção de palma forrageira deve-se considerar principalmente a relação entre os carboidratos fibrosos e não-fibrosos totais, no tocante a manutenção da saúde e função ruminal normal. Ferreira et al. (2011) sugerem um nível máximo de CNF em dietas a base de palma forrageira próximo de $44 \%$, no tocante a saúde e função ruminal normais e adequado desempenho animal.

Observou-se consumos médios de proteína bruta de 91g/animal/dia, suficiente para promover ganho de peso de aproximadamente 100g/animal/dia (NRC, 2007), valor que pode ser considerado baixo. No entanto, é preciso atentar para a condição regional no tocante a disponibilidade de alimento concentrado, promovendo de forma afirmativa o caráter de sustentabilidade dos sistemas de produção.

O conhecimento da digestibilidade dos nutrientes é essencial para elaboração de planos nutricionais mais eficientes, que supram as exigências dos animais. Observa-se que a inclusão dos diferentes suplementos à dieta não promoveu alterações na digestibilidade aparente da MS, MO, PB e dos carboidratos (Tabela 4).

Wanderley et al. (2012), trabalhando com ovinos alimentados com palma forrageira associada a diferentes volumosos em proporção semelhante ao do presente estudo, observaram digestibilidade aparente média da matéria seca e da matéria orgânica de 61,6 e $63,1 \%$, respectivamente, muito próximas as observadas no presente estudo. Misra et al. (2006) afirmaram que a suplementação nitrogenada é essencial para melhorar $\mathrm{o}$ valor nutricional de dietas a base de palma forrageira. Estes autores observaram 
Rev. Bras. Saúde Prod. Anim., Salvador, v.14, n.3, p.508-517 jul./set., 2013 http://www.rbspa.ufba.br ISSN 15199940

efeito positivo da inclusão de farelo de amendoim sobre a digestibilidade aparente da MS em dietas a base de palma forrageira. Segundo os mesmos autores, o nitrogênio suplementar melhora a atividade microbiana no rúmen, proporcionando melhor aproveitamento da dieta.

Tabela 4. Digestibilidade aparente dos nutrientes e teor de energia (NDT) das dietas

\begin{tabular}{|c|c|c|c|c|c|c|}
\hline \multirow[b]{2}{*}{ Nutriente } & \multicolumn{5}{|c|}{ Rações } & \multirow[b]{2}{*}{ CV $(\%)$} \\
\hline & $\begin{array}{c}\text { Sem } \\
\text { Suplemento }\end{array}$ & $\begin{array}{c}\text { Farelo de } \\
\text { Trigo }\end{array}$ & $\begin{array}{c}\text { Farelo de } \\
\text { Soja }\end{array}$ & $\begin{array}{l}\text { Farelo de } \\
\text { Algodão }\end{array}$ & $\begin{array}{c}\text { Caroço de } \\
\text { Algodão }\end{array}$ & \\
\hline CDMS & $60,90^{\mathrm{a}}$ & $62,91^{\mathrm{a}}$ & $59,88^{\mathrm{a}}$ & $61,73^{\mathrm{a}}$ & $57,65^{\mathrm{a}}$ & 5,13 \\
\hline CDMO & $67,53^{\mathrm{a}}$ & $68,09^{\mathrm{a}}$ & $66,05^{\mathrm{a}}$ & $66,30^{\mathrm{a}}$ & $63,25^{\mathrm{a}}$ & 4,45 \\
\hline CDPB & $75,45^{\mathrm{a}}$ & $76,94^{\mathrm{a}}$ & $77,73^{\mathrm{a}}$ & $76,14^{\mathrm{a}}$ & $75,58^{\mathrm{a}}$ & 4,13 \\
\hline CDEE & $84,49^{b}$ & $82,35^{\mathrm{b}}$ & $83,64^{b}$ & $84,03^{b}$ & $91,05^{\mathrm{a}}$ & 3,32 \\
\hline CDCNF & $88,81^{\mathrm{a}}$ & $88,31^{\mathrm{a}}$ & $87,29^{\mathrm{a}}$ & $86,25^{\mathrm{a}}$ & $84,93^{\mathrm{a}}$ & 5,60 \\
\hline CDFDN & $42,33^{\mathrm{a}}$ & $44,80^{\mathrm{a}}$ & $43,73^{\mathrm{a}}$ & $42,13^{\mathrm{a}}$ & $39,05^{\mathrm{a}}$ & 15,24 \\
\hline $\mathrm{NDT}^{1}$ & $62,46^{\mathrm{a}}$ & $63,25^{\mathrm{a}}$ & $61,14^{\mathrm{a}}$ & $61,67^{\mathrm{a}}$ & $61,61^{\mathrm{a}}$ & 4,54 \\
\hline
\end{tabular}

Médias, na linha, seguidas por letras diferentes, diferem $(\mathrm{P}<0,05)$ pelo teste Tukey.

${ }^{1} \%$ na matéria seca; $\mathrm{CV}$ = coeficiente de variação.

Coeficientes de digestibilidade aparente da: $\mathrm{CDMS}=$ matéria seca, $\mathrm{CDMO}=$ matéria orgânica, $\mathrm{CDPB}=$ proteína bruta, $\mathrm{CDEE}=$ extrato etéreo, $\mathrm{CDFDN}=$ fibra em detergente neutro, $\mathrm{CDCNF}=$ carboidratos não-fibrosos; NDT $=$ nutrientes digestíveis totais.

Considerando o alto teor de extrato etéreo do caroço de algodão e a alta digestibilidade deste nutriente, observou-se maior CEE e maior CDEE para a dieta onde o caroço de algodão foi utilizado como suplemento.

Os diferentes suplementos utilizados foram fornecidos na forma de mistura completa e em baixa concentração na MS total, e não promoveram alterações nos consumos de proteína bruta e carboidratos (Tabela 3), estes últimos, de maior relevância para dietas a base de palma forrageira no que diz respeito à relação entre fibrosos e não fibrosos (PESSOA et al., 2009). O pH ruminal não sofreu influência em função dos suplementos utilizados (Tabela 5), mas apresentou comportamento quadrático em função dos tempos de coleta após a alimentação (Figura 1). O pH mínimo foi estimado em 6,45, 4,08 horas após a alimentação.

Tabela 5. pH no líquido ruminal

\begin{tabular}{|c|c|c|c|c|c|c|c|c|}
\hline \multirow[t]{2}{*}{ Item } & \multicolumn{5}{|c|}{ Rações } & \multicolumn{3}{|c|}{ Efeito $(P$-Valor $)$} \\
\hline & SS & FT & FS & FA & CA & Trat & Tempo & Trat*Tempo \\
\hline $\mathrm{pH}$ & 6,50 & 6,60 & 6,59 & 6,55 & 6,60 & 0,4488 & $<0,0001$ & 0,8537 \\
\hline \multicolumn{9}{|c|}{ Desdobramento Efeito Tempo } \\
\hline Item & \multicolumn{5}{|c|}{ Tempo (h) } & \multicolumn{3}{|c|}{ Contrastes $(P$-Valor $)$} \\
\hline & 0 & & 2 & 4 & 6 & Linear & Quad. & Cúbico \\
\hline $\mathrm{pH}$ & 6,7 & & 57 & 6,42 & 6,52 & $<0,0001$ & $<0,0001$ & 0,1299 \\
\hline
\end{tabular}

$\mathrm{SS}=$ sem suplemento, $\mathrm{FT}=$ farelo de trigo, $\mathrm{FS}=$ farelo de soja, $\mathrm{FA}=$ farelo de algodão, $\mathrm{CA}=$ caroço de algodão. 


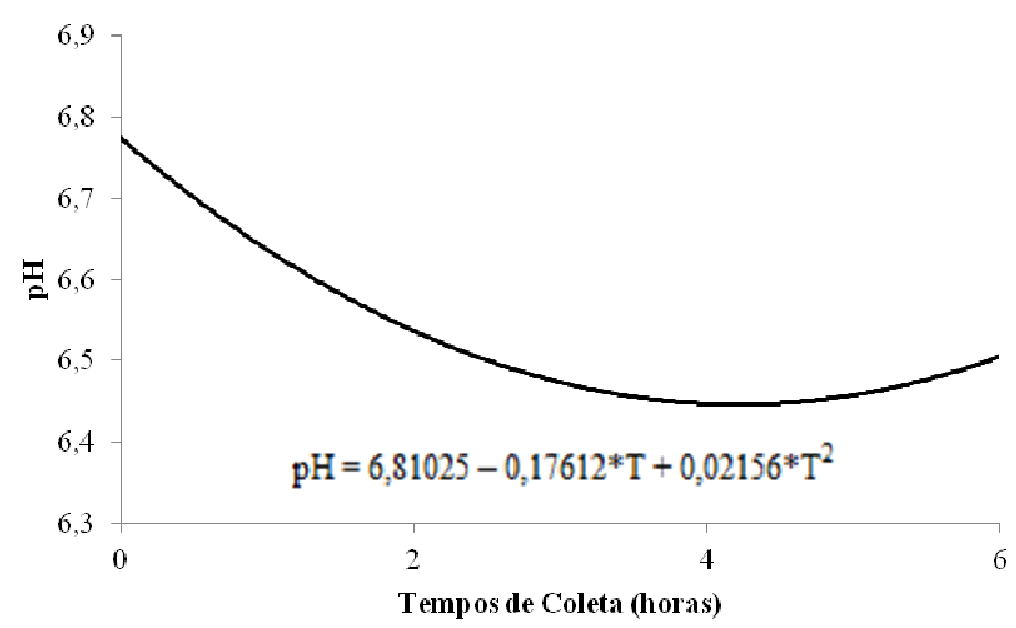

Figura 1. pH do líquido ruminal em diferentes tempos de coleta

$\mathrm{O}$ pH é influenciado pelo tipo de alimentação consumida e sua estabilização é devida em grande parte à saliva, que possui alto poder tamponante (Van SOEST, 1994). A proporção entre carboidratos fibrosos e não fibrosos nas dietas experimentais manteve-se de forma a proporcionar condições normais de saúde ruminal, uma vez que as bactérias do rúmen são adaptadas para se multiplicarem em meio com pH entre 5,5 a 7,0 (HOOVER \& STOKES, 1991).

A oferta da dieta na forma de ração completa contribuiu na manutenção do $\mathrm{pH}$ ruminal dentro da faixa considerada ideal por Hoover \& Stokes (1991). De acordo com Pessoa et al. (2004), em dietas a base de palma forrageira $o$ fornecimento na forma completa possibilita um padrão mais constante de fermentação ruminal. Santos et al. (2010), fornecendo dieta com 73\% de palma forrageira associada ao feno de tifton na forma de mistura completa para ovinos, observaram $\mathrm{pH}$ ruminal médio de 6,49.

Avaliando a inclusão do feno de tifton em dietas a base de palma forrageira para caprinos, Vieira et al. (2008) observaram valores de $\mathrm{pH}$ e $\mathrm{NH}_{3}$ no rúmen de 5,9 e $12,9 \mathrm{mg} / 100 \mathrm{~mL}$, respectivamente, para a proporção de palma semelhante a utilizada no presente estudo (67\% na MS). Os autores relataram que para esta proporção observou-se maximização do CMS.

No estudo, não se observou efeitos significativos da inclusão dos diferentes suplementos sobre a concentração de N$\mathrm{NH}_{3}$ no líquido ruminal (Tabela 6). No entanto, observou-se comportamento quadrático em função dos tempos de coleta após a alimentação (Figura 2). $\mathrm{O}$ pico na concentração de amônia foi estimado em $13,89 \mathrm{mg} / 100 \mathrm{~mL}$ às 3,8 horas após a alimentação.

Wanderley et al. (2012) observaram concentrações de amônia no líquido ruminal de ovinos recebendo dietas com $61 \%$ de palma forrageira muito próximas as observados no presente estudo (média de 12,5mg/100mL). Bispo et al. (2007) observaram concentração de amônia de $12,4 \mathrm{mg} / 100 \mathrm{~mL}$ em dietas com $56 \%$ de palma forrageira para ovinos. De acordo com Leng (1990), são necessárias concentrações de amônia no líquido ruminal entre 10 e $20 \mathrm{mg} / 100 \mathrm{~mL}$, visando promover adequada utilização dos nutrientes em dietas à base de forragem com reduzido teor de nitrogênio. 
Rev. Bras. Saúde Prod. Anim., Salvador, v.14, n.3, p.508-517 jul./set., 2013 http://www.rbspa.ufba.br ISSN 15199940

Tabela 6. Concentração de amônia $\left(\mathrm{N}-\mathrm{NH}_{3}\right)$ no líquido ruminal $(\mathrm{mg} / 100 \mathrm{~mL})$

\begin{tabular}{|c|c|c|c|c|c|c|c|c|}
\hline \multirow[t]{2}{*}{ Item } & \multicolumn{5}{|c|}{ Rações } & \multicolumn{3}{|c|}{ Efeito (P-Valor) } \\
\hline & SS & FT & FS & FA & CA & Trat & Tempo & Trat*Tempo \\
\hline $\mathrm{N}-\mathrm{NH}_{3}$ & 11,35 & 10,05 & 12,68 & 11,05 & 12,22 & 0,5612 & $<0,0001$ & 0,4547 \\
\hline \multicolumn{9}{|c|}{ Desdobramento Efeito Tempo } \\
\hline Item & \multicolumn{5}{|c|}{ Tempo (h) } & \multicolumn{3}{|c|}{ Contrastes (P-Valor) } \\
\hline & 0 & & & 4 & 6 & Linear & Quad. & Cúbico \\
\hline $\mathrm{N}-\mathrm{NH}_{3}$ & 7,68 & & & 13,65 & 11,93 & $<0,0001$ & $<0,0001$ & 0,1318 \\
\hline
\end{tabular}

$\mathrm{SS}=$ sem suplemento, $\mathrm{FT}=$ farelo de trigo, $\mathrm{FS}=$ farelo de soja, $\mathrm{FA}=$ farelo de algodão, $\mathrm{CA}=$ caroço de algodão.

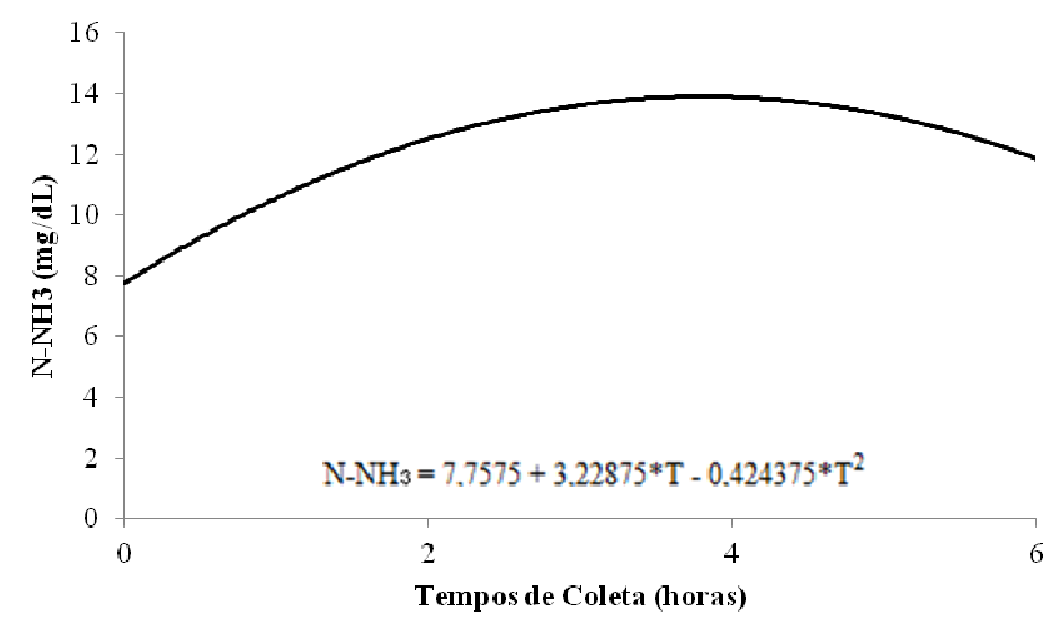

Figura 2. Concentração de $\mathrm{N}-\mathrm{NH}_{3}$ no líquido ruminal em diferentes tempos de coleta.

Quando o nitrogênio é ministrado ao animal ruminante com quantidade inadequada de energia disponível no rúmen, observa-se elevação na concentração de amônia no líquido ruminal (Van SOEST, 1994). No presente estudo, constata-se a adequação na associação da palma forrageira à uréia e aos suplementos, uma vez que a mistura pressupõe adequada sincronização entre 0 suprimento de energia e nitrogênio para os microorganismos ruminais, considerando a alta concentração de carboidratos solúveis na palma, o que facilita a incorporação do nitrogênio suplementar na proteína microbiana, principal fonte de proteína metabolizável para o animal hospedeiro
(PESSOA et al., 2009). Desta forma, o teor de proteína da palma, insuficiente para o adequado desempenho animal, pode ser aumentado.

A associação do farelo de trigo ou farelo de soja, farelo de algodão ou caroço de algodão a dieta a base de palma forrageira, bagaço de cana-deaçúcar e uréia, nas proporções estudadas, não altera o consumo, a digestibilidade aparente dos nutrientes, o $\mathrm{pH}$ e a concentração ruminal de $\mathrm{N}$ $\mathrm{NH}_{3}$. Portanto, podem ser utilizados de acordo com a conveniência do produtor, representando importante alternativa, pois, simplifica as práticas de manejo. Outras pesquisas avaliando o desempenho animal devem ser realizadas. 
Rev. Bras. Saúde Prod. Anim., Salvador, v.14, n.3, p.508-517 jul./set., 2013 http://www.rbspa.ufba.br ISSN 15199940

\section{REFERÊNCIAS}

BISPO, S.V.; FERREIRA, M.A.; VÉRAS, A.S.C.; BATISTA, A.M.; PESSOA, R.A.S.; BLEUEL, M.P. Palma forrageira em substituição ao feno de capim-elefante. Efeito sobre consumo, digestibilidade e características de fermentação ruminal em ovinos. Revista

Brasileira de Zootecnia, v.36, n.6, p.1902-1909, 2007.

BRYANT, M.P. Nutritional requirements of the predominant rumen cellulolytic bacteria. Federation Proceedings, v.32, n.7, p.1809-1813, 1973.

CABRAL, L.S.; VALADARES FILHO, S.C.; DETMANN, E.; ZERVOUDAKIS, J.T.; SOUZA, A.L.; VELOSO, R.G. Eficiência microbiana e parâmetros ruminais em bovinos alimentados com dietas à base de volumosos tropicais. Revista Brasileira de Zootecnia, v.37, n.5, p.919-925, 2008.

CASALI, A.O.; DETMANN, E.; VALADARES FILHO, S.C.; PEREIRA, J.C.; HENRIQUES, L.T.; FREITAS, S.G.; PAULINO, M.F. Influência do tempo de incubação de partículas sobre os teores de compostos indigestíveis em alimentos e fezes bovinas obtidos por procedimentos in situ. Revista Brasileira de Zootecnia, v.37, n.2, p.335-342, 2008.

DETMANN, E.; SOUZA, M.A.; VALADARES FILHO, S.C.; QUEIROZ, A.C.; BERCHIELLI, T.T.; SALIBA, E.O.S.; CABRAL, L.S.; PINA, D.S.; LADEIRA, M.M.; AZEVEDO, J.A.G. Métodos para análise de alimentos INCT - Ciência Animal. Visconde do Rio Branco: Suprema, 2012. 214p.

FERREIRA, M.A.; PESSOA, R.A.S.; SILVA, F.M.; BISPO, S.V. Palma forrageira e uréia na alimentação de vacas leiteiras. Recife: Universidade Federal Rural de Pernambuco, 2011. 40p.

HOOVER, W.H.; STOKES, S.R. Balancing carbohydrates and proteins for optimium rumen microbial yield. Journal of Dairy Science, v.74, n.10, p.3630-344, 1991.

KAPS, A.M.; LAMBERSON, W.R. Biostatistics for animal science. London: CABI Publishing, 2004. 445p.

LENG, R.A. Factors affecting the utilization of "poor-quality" forages by ruminants particularly under tropical conditions. Nutrition Research Reviews, v.3, n.3, p.277-303, 1990.

MISRA, A.K.; MISHRA, A.S.; TRIPATHI, M.K.; CHATURVEDI, O.H.; VAITHIYANATHAN, S.; PRASAD, R.; JAKHMOLA, R.C. Intake, digestion and microbial protein synthesis in sheep on hay supplemented with prickly pear cactus [Opuntia ficusindica (L.) Mill.] with or without groundnut meal. Small Ruminant Research, v.63, n.1-2, p.125-134, 2006.

NATIONAL RESEARCH COUNCIL NRC. Nutrient requirements of small ruminants: sheep, goats, cervids and new camelids. Washington, DC: National Academy Press, 2007. 384p.

PESSOA, R.A.S.; FERREIRA, M.A.; LIMA, L.E.; LIRA, M.A.; VÉRAS, A.S.C.; SILVA, A.E.V.N.; SOSA, M.Y.; AZEVEDO, M.; MIRANDA, K.F.; SILVA, F.M.; MELO, A.A.S.; LÓPEZ, O.R.M. Desempenho de vacas leiteiras submetidas a diferentes estratégias alimentares. Archivos de zootecnia, v.53, n.203, p.309-320, 2004. 
Rev. Bras. Saúde Prod. Anim., Salvador, v.14, n.3, p.508-517 jul./set., 2013 http://www.rbspa.ufba.br ISSN 15199940

PESSOA, R.A.S; LEÃO, M.I.; FERREIRA, M.A.; VALADARES FILHO, S.C.; VALADARES, R.F.D; QUEIROZ, A.C.Q. Balanço de compostos nitrogenados e produção de proteína microbiana em novilhas leiteiras alimentadas com palma forrageira, bagaço de cana-deaçúcar e uréia associados a diferentes suplementos. Revista Brasileira de Zootecnia, v.38, n.5, p.941-947, 2009.

SANTOS, A.O.A.; BATISTA, A.M.V.; MUSTAFA, A.F.; AMORIM, G.L.; GUIM, A.; MORAES, A.C.; LUCENA, R.B.; ANDRADE, R. Effects of bermudagrass hay and soybean hulls inclusion on performance of sheep fed cactus-based diets. Tropical Animal Health and Production, v.42, n.4, p.487-494, 2010.

SOARES, C.A.; CAMPOS, J.M.S.; VALADARES FILHO, S.C.; VALADARES, R.F.D.; MENDONÇA, S.S.; QUEIROZ, A.C.; LANA, R.P. Consumo, digestibilidade aparente, produção e composição do leite de vacas leiteiras alimentadas com farelo de trigo. Revista Brasileira de

Zootecnia, v.33, n.6, p.2161-2169, 2004.

SAS Institute. User's guide. Version 8. Cary, 2000.

TEGEGNE, F.; KIJORA, C.; PETERS, K.J. Study on the optimal level of cactus pear (Opuntia ficus-indica) supplementation to sheep and its contribution as source of water. Small Ruminant Research, v.72, n.2-3, p.157-164, 2007.
Van SOEST, P.J. Nutritional ecology of the ruminants. 2.ed. Ithaca: Cornell University Press, 1994. 476p.

VIEIRA, E.L.; BATISTA, A.M.V.; GUIM, A.; CARVALHO, F.F.R.; NASCIMENTO, A.C.; ARAÚJO, R.F.S.; MUSTAFA, A.F. Effects of hay inclusion on intake, in vivo nutrient utilization and ruminal fermentation of goats fed spineless cactus (Opuntia ficus-indica Mill) based diets. Animal

Feed Science and Technology, v.141, n.3-4, p.199-208, 2008.

WANDERLEY, W.L; FERREIRA, M.A.; BATISTA, A.M.V.; VÉRAS, A.S; BISPO, S.V.; SILVA, F.M.; SANTOS, V.L.F. Consumo, digestibilidade e parâmetros ruminais em ovinos recebendo silagens e fenos em associação à palma forrageira.

\section{Revista Brasileira de Saúde e}

Produção Animal [online], v.13, n.2, p.444-456, 2012.

Data de recebimento: 06/03/2013

Data de aprovação: 06/09/2013 